\title{
EMDOGAIN (EMD) AND PLATELET-RICH PLASMA (PRP) IN PERIODONTAL REGENERATION
}

\author{
Mariya Miteva \\ Department of Periodontology and Dental Implantology, Faculty of Dental Medicine, \\ Medical University of Varna
}

\begin{abstract}
Periodontitis is a major cause of adult tooth loss and is characterized by bacteria-induced inflammation and periodontal destruction. The ultimate goal of periodontal therapy is not only to slow down the development of periodontal disease, but also to regenerate the architectural and functional integrity of the periodontal complex, which includes the formation of new cementum together with a new connective tissue attachment between the newly formed bone and cementum.
\end{abstract}

Keywords: periodontitis, regeneration, EMD, PRP

\section{INTRODUCTION}

Periodontitis is a major cause of adult tooth loss and is characterized by bacteria-induced inflammation and periodontal destruction. The ultimate goal of periodontal therapy is not only to slow down the development of periodontal disease, but also to regenerate the architectural and functional integrity of the periodontal complex, which includes the formation of new cementum together with a new connective tissue attachment between the newly formed bone and cementum (1).

Regeneration uses the principles of guided tissue regeneration (GTR) (2) and guided bone regeneration (GBR) as modern techniques in implantolo-

Address for correspondence:

Mariya Miteva

Faculty of Dental Medicine

Medical University of Varna

84 Tzar Osvoboditel Blvd

9000 Varna

e-mail:miteva_mariq@abv.bg

Received: May 14, 2019

Accepted: June 3, 2019 gy and periodontology. Their main goal is to restore lost tissues, creating a perfect condition for implant placement or tooth preservation.

\section{Periodontal Regeneration}

Periodontal regeneration uses bone restorative materials to "fill" periodontal defects. Many techniques have been developed focusing on the search for the ideal materials for regeneration - autograft, allograft, xenograft and various artificial bone replacements (3). The autograft is considered a gold standard for periodontal regeneration. Other alternatives are used to restore the periodontium to avoid a second surgical site and complications such as ankylosis and root resorption. Various allografts, xenografts, and synthetic materials such as DFDBA, inorganic bovine bone, hydroxyapatite (HA) and tricalcium phosphate (TCP) are available and widely used materials. Also, biocomposite hydroxyapatite is successfully used for periodontal regeneration (4). Some authors report full bone regeneration and high volume stability around implants using high porosity synthetic biphasic calcium phosphate, sintered deproteinized bovine bone mineral, and synthetic twophase nano-hydroxyapatite paste in combination with a pericardial collagen membrane (5). 
The use of biological mediators may selectively increase cell repopulation in the periodontium. Combination of biologically active agents with scaffold materials may positively influence the treatment of intraosseous defects (6). EMD, PRP, PRF, biomaterials derived from human organisms or animals have been extensively investigated and clinically administered in periodontal regeneration (7-13).

\section{EMD in Periodontal Regeneration}

In recent decades EMD has been available as a biological regenerative material. It is derived from the developing porcine teeth and contains a mixture of low-molecular weight proteins that can be absorbed on the hydroxyapatite and collagen fibers at the root surface and cause cementum formation (7-9). EMD induces angiogenesis of human microvascular cells (14). EMD acts as a cytostatic agent on cultured epithelial cells and can thus favor regeneration of the periodontium by inhibiting or delaying epithelial regeneration (10).

Its effects are compared with those with open flap debridement (OFD) and other surgical procedures such as GTR or combined approaches in the treatment of periodontal intraosseous defects $(8,15$ 17). OFD followed by further administration of EMD may lead to significantly greater clinical attachment gain compared to OFD used alone $(17,18)$. Most studies show that there is almost no advantage of EMD when used with bone graft materials (bovine bone mineral, nanocrystalline hydroxyapatite and biphasic calcium phosphate) (13,19-22).

Several studies show histological evidence of periodontal regeneration using EMD (9,23-26). EMD was observed on the root surface for 4 weeks postapplication, and early signs of regeneration were observed after 2 to 6 weeks $(27,28)$.

EMD has been shown to achieve an average reduction in probing depth (PD) of 3.8 to $4.9 \mathrm{~mm}$ and an average clinical attachment level (CAL) of 2.2 to $3.4 \mathrm{~mm},(8,17,29-31)$ as well as $74 \%$ bone fill of the defect (17).

Because of its semi-liquid consistency, EMD has a limited space-building potential, which in turn can lead to collapse of the flap (23). The bone restorative material helps to overcome the risk of collapse of the flap after application of EMD, especially in deep intraosseus defects and provide space for the regener- ation process and at the same time allows the EMD to support periodontal regeneration (32). Boyan et al (33) have found that the addition of $4 \mathrm{mg}$ of EMD to DFDBA increases the amount of bone induction and new bone formation compared to DFDBA alone. Rosen (34) demonstrates the clinical benefits of using a combined therapeutic approach where EMD is combined with DFDBA or FDBA. Harrelet al. successfully used DFDBA mixed with EMD with minimally invasive surgery to treat 130 periodontal defects (35). Hoidal et al. (19) found that the addition of EMD to DFDBA did not provide a statistically sig nificant improvement in measured soft and hard tissue parameters compared to DFDBA alone 6 months after surgery.

In 2002, Velasquez-Plata et al. (36) examined the use of EMD alone or in combination with xenograft and did not detect a significant difference between the groups with respect to PD reduction or CAL gain. Lekovic et al. (37) show a greater reduction in probing depth, clinical attachment gain, and bone fill with a combination of xenograft and EMD compared to EMD alone.

In an attempt to determine whether bone fill material plays a role in the potential beneficial effects of EMD addition, Gurinsky et al. (38) examined the combination of DFDBA and EMD and EMD alone, demonstrating significantly more bone filling in the combined group but no difference in probing depth reduction and clinical attachment gain.

In summary, EMD is a protein preparation of developing porcine teeth that contains a mixture of low-molecular weight proteins. When applied to the root surface, the proteins are absorbed into the hydroxyapatite and collagen fibers, causing cement formation, followed by periodontal regeneration. Clinical use of EMD may be characterized as safe with excellent clinical outcomes and limited complications. EMD alone or in combination with bone graft materials provides excellent clinical outcome and longterm stability $(8,29)$.

\section{PRP in Periodontal Regeneration}

PRP and PRF are the two generations of platelet concentrates obtained by treating autogenous blood samples by centrifugation. PRP is an autologous highly concentrated platelet product (39) and its preparation requires anticoagulants at the time of 
taking blood-thymidine and calcium chloride. This product is derived from a centrifuged blood sample that contains high concentration of platelet growth factors, insulin-like growth factor, and fibroblast growth factor (40). In addition, the lower $\mathrm{pH}$ of PRP (6.5-6.7) compared to normal blood (7-7.2) can increase bacteriostatic and bactericidal properties (41). Unlike PRP, PRF is centrifuged blood without any additives (10).

Both PRP and PRF contain highly concentrated growth factors such as transforming growth factorb (TGF-b), platelet derived growth factor (PDGF), vascular growth factor (VEGF), insulin-like growth factor (IGF), epithelial growth factor, and fibroblast growth factor-b (FGF-b)(42).

Wiltfanget al. (43) evaluated immunohistologically the use of PRP in the regeneration of bone defects of the skull of minipigs by treating them with $b$ TCP with or without PRP and found that the addition of PRP did not affect bone regeneration and did not add any additional benefit. The same team (44) compared b-TCP and PRP / b-TCP sinus floor elevations at the 6th month and reported 8 to $10 \%$ more bone formation with PRP / b-TCP, but the difference was statistically insignificant.

Velichet et al. (45) evaluated the efficacy of bTCP and hydroxyapatite bone graft materials and the PRP / b-TCP combination in the treatment of mandibular defects reporting that all treatment approaches were successful and the PRP / b-TCP group showed a faster formation of new bone and bone remodeling at the end of the first year.

Dori et al. (46) treated periodontal intraosseus defects with a combination of b-TCP / GTR with or without PRP and at the end of the first year no statistically significant differences were observed in any of the clinical parameters in either group and no additional clinical benefits for PRP.

In an experimental study, Kovacs et al. (47) compared b-TCP and PRP / b-TCP combinations and assessed histologically the bone formation in bone defects after premolar extraction in dog lower jaw. They found significantly greater bone formation in the PRP / b-TCP group at week 12. In another experimental study of similar design, Kovacs et al. (48) reported a significant difference in favor of the PRP / b-TCP group at week 12 and concluded that the use of PRP accelerated remodeling of b-TCP and resulted in the formation of bone with a quality similar to autogenous bone.

Yassibag-Berkman et al. (49) evaluated the efficacy of b-TCP, PRP / b-TCP, and PRP / b-TCP / GTR in the treatment of two- and three-wall intraosseous defects, and reported an improvement in all parameters tested compared to the baseline.However, PRP did not add significant clinical benefit after 6 months. These results are confirmed by other authors (50).

Some studies (51-53) have shownthat optimal clinical results with GTR in combination with bone graft materials with or without PRP have been obtained in the first year following regenerative therapy of intraosseous defects.

S. Peev and D. Atanasov (54) have shown in theirown research on 86 implants that the use of PRP withimmediate loaded implants improves the stability.

\section{CONCLUSION}

The data on the different approaches are contradictory and therefore more research is needed. The combination of EMD and bone grafts may result in additional clinical improvements in terms of CAL gain and PD reduction compared with those obtained with EMD alone. Platelet-derived concentrates have been shown to enhance soft tissue healing which indirectly can create a better environment for bone growth.Futurestudiestestingthe efficacy of this materials promoting GBR, GTR and treatment of peri-implant defects are needed.

\section{REFERENCES}

1. Wang HL, Greenwell H, FiorelliniJ. Periodontal regeneration. J Periodontol. 2005;76(9):1601-22.doi: 10.1902/jop.2005.76.9.1601.

2. Quinones CR, Carellas IG, Caffessee RG. Guided periodontal tissue regeneration (GPTR): an update. Pract Periodontics Aesthet Dent. 1996;8(2):169-80.

3. Kao RT, Conte G, Nishimine D. Tissue engineering for periodontal regeneration.J Calif Dent Assoc. 2005;33(3):205-15.

4. Stramazzotti D, Coiana C, ZizziA. Impactofsmokingonguidedtissueregeneration using a biocomposite poly (lactic-co-glycolic) acid/sub-micron size hydroxyapatite with a rubberdamasan- 
alternativebarrier.Int J ImmunopatholPharmacol. 2015;28(1):21-8. doi: 10.1177/0394632015573159.

5. Peev S, Gusiyska A, Sabeva E. Guided bone regeneration and simultaneous implant placement. Int J SciRes(IJSR). 2016; 5(2): 1529-30.

6. KaoRT, NaresS, ReynoldsMA. Periodontal regeneration-intrabony defects: a systematic review from the AAP regeneration workshop. J Periodontol. 2015;86(2 Suppl):S77-104. doi: 10.1902/ jop.2015.130685.

7. Thorat M, Pradeep AR, Pallavi B. Clinical effect of autologous platelet-rich fibrin in the treatment of intrabony defects: A controlled clinical trial.J ClinPeriodontol. 2011;38(10):925-32. doi: 10.1111/j.1600-051X.2011.01760.x.

8. Sculean A, Donos N, Schwarz F, Becker J, Brecx M, et al. Five-year results following treatment of intrabony defects with enamel matrix proteins and guided tissue regeneration. J Clin Periodontol. 2004;31(7):545-9.doi: 10.1111/j.1600-051X.2004.00518.x.

9. Yukna RA, Mellonig JT. Histologic evaluation of periodontal healing in humans following regenerative therapy with enamel matrix derivative. A 10-case series. J Periodontol. 2000;71(5):752-9.doi: 10.1902/jop.2000.71.5.752.

10. Choukroun J, Adda F, Schoeffler C. An opportunity in perio-implantology: The PRF.Implantodontie. 2001;42:55-62.

11. Rana MP, Mehrotra N. Human amniotic membrane: hope in periodontal regeneration. Int JSciRes (IJSR). 2016; 5(4):564-9.

12. Mishra S, Singh S. Human amniotic membrane: Can it be a ray of hope in periodontal regeneration? Indian J Med Res. 2014; 3(9):118-21.

13. Tu Y-K, Woolston A, Faggion CM. Do bonegrafts or barrier membranes provide additional treatment efects for infrabony lesions treated with enamel matrix derivatives? A network meta-analysis of randomized-controlled trials. J Clin Periodontol. 2010; 37(1):59-79. doi:10.1111/j.1600-051X.2009.01499.x.

14. Aspriello SD, Zizzi A, Spazzafumo L. Effects of enamel matrix derivative on vascular endothelial growth factor expression and microvessel density in gingival tissues of periodontal pocket: a comparative study. J Periodontol. 2011;82(4):606-12. doi: 10.1902/jop.2010.100180.
15. Siciliano VI, Andreuccetti G, Siciliano AI, Blasi A, Sculean A, Salvi GE.Clinicaloutcomesaftert reatmentofnon-contained intrabony defects with enamel matrix derivative or guided tissue regeneration: a 12-month randomized controlled clinical trial. J Periodontol. 2011;82(1):62-71. doi: 10.1902/ jop.2010.100144.

16. Crea A, Dassatti L, Hofmann O, Zafropoulos G-G, Deli G. Treatment of intrabony defects using guided tissue regeneration or enamel matrix derivative: A 3-year prospective randomized clinical study. J Periodontol. 2008 Dec;79(12):2281-9. doi: 10.1902/ jop.2008.080135.

17. Froum SJ, Weinberg MA, Rosenberg E, Tarnow D. A comparative study utilizing open fap debridement with and without enamel matrix derivative in the treatment of periodontal intrabony defects: A 12-month re-entry study. J Periodontol. 2001;72(1):25-34.doi: 10.1902/jop.2001.72.1.25.

18. Silvestri M, Ricci G, Rasperini G. Comparison of treatments of intrabony defects with enamel matrix derivative, guided tissue regeneration with a nonresorbable membrane and Widman modified flap. A pilot study. J Clin Periodontol. 2000;27(8):603-10. doi:10.1034/j.1600-051x.2000.027008603.x.

19. Hoidal MJ, Grimard BA, Mills MP, Schoolfeld JD, Mellonig JT, Mealey BL. Clinical evaluation of demineralized freeze-dried bone allograf with and without enamel matrix derivative for the treatment of periodontal osseous defects in humans. J Periodontol. 2008;79(12):2273-80. doi: 10.1902/ jop.2008.080259.

20. Sculean A, Windisch P, Keglevich T, Chiantella GC, Gera I, Donos N. Clinical and histologic evaluation of human intrabony defects treated with an enamel matrix protein derivative combined with a bovine-derived xenograf. Int J Periodontics Restorative Dent. 2003;23(1):47-55.

21. Scheyer ET, Velasquez-Plata D, Brunsvold MA, Lasho DJ, Mellonig JT. A clinical comparison of a bovine-derived xenograf used alone and in combination with enamel matrix derivative for the treatment of periodontal osseous defects in humans. J Periodontol. 2002;73(4):423-32.doi: 10.1902/ jop.2002.73.4.423.

22. AlMachot E, Hofmann T, Lorenz K, Khalili I, Noack B.Clinical outcomes afer treatment of periodontal intrabony defects with nanocrystalline hydroxyapatite (Ostim) or enamel matrix derivatives (Emdogain): a randomized controlled clini- 
cal trial. Biomed Res Int. 2014;2014:786353. doi: $10.1155 / 2014 / 786353$.

23. Mellonig JT. Enamel matrix derivative for periodontal reconstructive surgery: Technique and clinical and histologic case report. Int J Periodontics Restorative Dent. 1999;19(1):8-19.

24. Heijl L. Periodontal regeneration with enamel matrix derivative in one human experimental defect. A case report. J Clin Periodontol. 1997;24(9 Pt 2):693-6.

25. Majzoub Z, Bobbo M, Atiyeh F, Cordioli G. Two patterns of histologic healing in an intrabony defect following treatment with enamel matrix derivative: A human case report. Int J Periodontics Restorative Dent. 2005;25(3):283-94.

26. Sculean A, Donos N, Windisch P. Healing of human intrabony defects following treatment with enamel matrix proteins or guided tissue regeneration. J PeriodontalRes. 1999;34(6):310-22.

27. Sculean A, Windisch P, Keglevich T, Fabi B, Lundgren E, Lyngstadaas PS. Presence of an enamel matrix protein derivative on human teeth following periodontal surgery. Clin Oral Investig. 2002;6(3):183-7. doi: 10.1007/s00784-002-0171-6.

28. Sculean A, Junker R, Donos N, Windisch P, Brecx M, Dünker N. Immunohistochemical evaluation of matrix molecules associated with wound healing following treatment with an enamel matrix protein derivative in humans. Clin Oral Investig. 2003;7(3):167-74.doi: 10.1007/s00784-003-0212-9.

29. Heijl L, Heden G, Svardstrom G, Ostgren A. Enamel matrix derivative (EMDOGAIN) in the treatment of intrabony periodontal defects. J Clin Periodontol. 1997;24(9 Pt 2):705-14.

30. Zetterstrom O, Andersson C, Eriksson L, Fredriksson A, Friskopp J, Heden G, et al. Clinical safety of enamel matrix derivative (EMDOGAIN) in the treatment of periodontal defects. J Clin Periodontol. 1997;24(9 Pt 2):697-704.

31. Sculean A, Windisch P, Chiantella GC, Donos N, Brecx M, Reich E. Treatment of intrabony defects with enamel matrix proteins and guided tissue regeneration. A prospective controlled clinical study. J ClinPeriodontol. 2001;28(5):397-403.

32. Döri F, Arweiler N, Gera I, Sculean A. Clinical evaluation of an enamel matrix protein derivative combined with either a natural bone mineral or beta-tricalcium phosphate.
J Periodontol. 2005;76(12):2236-43.doi: 10.1902/ jop.2005.76.12.2236.

33. Boyan BD, Weesner TC, Lohmann CH, Andreacchio D, Carnes DL, Dean DD, et al. Porcine fetal enamel matrix derivative enhances bone formation induced by demineralised freeze dried bone allograft in vivo. J Periodontol.2000;71(8):1278-86. doi:10.1902/jop.2000.71.8.1278.

34. Rosen PS, Reynolds MA. A retrospective case series comparing the use of demineralized freeze-dried bone allograft and freeze-dried bone allograft combined with enamel matrix derivative for the treatment of advanced osseous lesions. J Periodontol. 2002;73(8):942-9.doi: 10.1902/jop.2002.73.8.942.

35. Harrel SK, Wilson TG, Nunn ME. Prospective assessment of the use of enamel matrix proteins with minimally invasive surgery. J Periodontol. 2005;76(3):380-4.doi: 10.1902/jop.2005.76.3.380.

36. Velasquez-Plata D, Scheyer ET, Mellonig JT. Clinical comparison of an enamel matrix derivative used alone or in combination with a bovine-derived xenograft for the treatment of periodontal osseous defects in humans. J Periodontol. 2002;73(4):433-40.doi: 10.1902/jop.2002.73.4.433.

37. Lekovic V, Camargo PM, Weinlaender M, Nedic M, Aleksic Z, Kenney EB. A comparison between enamel matrix proteins used alone or in combination with bovine porous bone mineral in the treatment of intrabony periodontal defects in humans. J Periodontol. 2000;71(7):1110-6.doi: 10.1902/ jop.2000.71.7.1110.

38. Gurinsky BS, Mills MP, Mellonig JT. Clinical evaluation of demineralized freeze-dried bone allograft and enamel matrix derivative versus enamel matrix derivative alone for the treatment of periodontal osseous defects in humans. J Periodontol. 2004;75(10):1309-18.doi: 10.1902/ jop.2004.75.10.1309.

39. Marx RE, Carlson ER, Eichstaedt RM, Schimmele SR, Strauss JE, Georgeff KR. Platelet-rich plasma: Growth factor enhancement for bone grafts. Oral Surg Oral Med Oral Pathol Oral Radiol Endod. 1998;85(6):638-46.

40. Poorsattar Bejeh Mir A. Tissue engineering: Oromaxillofacial reconstruction with platelet rich plasma (PRP). Caspian J Dent Res. 2012;1(1):46-8.

41. Bashutski JD, Wang HL. Role of platelet-rich plasma in soft tissue root-coverage procedures: A review. Quintessence Int. 2008;39(6):473-83. 
42. Dohan DM, Choukroun J, Diss A. Platelet-rich fibrin (PRF): a second-generation platelet concentrate. Part I: Technological concepts and evolution. Oral Surg Oral Med Oral Pathol Oral Radiol Endod. 2006;101(3):e37-44.doi: 10.1016/j. tripleo.2005.07.008.

43. Wiltfang J, Kloss FR, Kessler P, Nkenke E, Schultze-Mosgau S, Zimmermann R, et al. Effects of platelet-rich plasma on bone healing in combination with autogenous bone and bone substitutes in critical-size defects. An animal experiment. Clin Oral Implants Res. 2004;15(2):187-93.

44. Wiltfang J, Schlegel KA, Schultze-Mosgau S, Nkenke E, Zimmermann R, Kessler P. Sinus floor augmentation with beta-tricalciumphosphate (betaTCP): Does platelet-rich plasma promote its osseous integration and degradation? Clin Oral Implants Res. 2003;14(2):213-8.

45. Velich N, Nemeth Z, Hrabak K, Suba Z, Szabo G. Repair of bony defect with combination biomaterials. J Craniofac Surg. 2004;15(1):11-5.

46. Dori F, Huszar T, Nikolidakis D, Tihanyi D, Horvath A, Arweiler NB, et al. Effect of platelet-rich plasma on the healing of intrabony defects treated with beta tricalcium phosphate and expanded polytetrafluoroethylene membranes. J Periodontol. 2008;79(4):660-9. doi: 10.1902/jop.2008.070473.

47. Kovacs K, Velich N, Huszar T, Szabo G, Semjen G, Reiczigel J, et al. Comparative study of beta-tricalcium phosphate mixed with platelet-rich plasma versus beta-tricalcium phosphate, a bone substitute material in dentistry. Acta Vet Hung. 2003;51(4):475-84.doi: 10.1556/AVet.51.2003.4.5.

48. Kovacs K, Velich N, Huszar T, Fenyves B, Suba Z, Szabo G. Histomorphometric and densitometric evaluation of the effects of platelet-rich plasma on the remodeling of beta-tricalcium phosphate in beagle dogs. J Craniofac Surg. 2005;16(1):150-4.
49. Yassibag-Berkman Z, Tuncer O, Subasioglu T, Kantarci A. Combined use of platelet-rich plasma and bone grafting with or without guided tissue regeneration in the treatment of anterior interproximal defects. J Periodontol. 2007;78(5):801-9.doi: 10.1902/jop.2007.060318.

50. Harnack L, Boedeker RH, Kurtulus I, Boehm S, Gonzales J, Meyle J. Use of platelet-rich plasma in periodontal surgery-A prospective randomised double blind clinical trial. Clin Oral Investig. 2009;13(2):179-87. doi: 10.1007/s00784-008-0223-7.

51. Döri F, Huszár T, Nikolidakis D,Arweiler NB, Gera I, Sculean A. Effect of platelet-rich plasma on the healing of intra-bony defects treated with a natural bone mineral and a collagen membrane. J Clin Periodontol. 2007;34(3):254-61.doi: 10.1111/j.1600-051X.2006.01044.x.

52. Döri F, Huszár T, Nikolidakis D,Arweiler NB, Gera I, Sculean A. Effect of platelet-rich plasma on the healing of intrabony defects treated with an anorganic bovine bone mineral and expanded polytetrafluoroethylene membranes. J Periodontol. 2007;78(6):983-90.doi: 10.1902/jop.2007.060349.

53. Christgau M, Moder D, Wagner J, Glässl M, Hiller KA, Wenzel A, et al. Influence of autologous platelet concentrate on healing in intrabony defects following guided tissue regeneration therapy: A randomized prospective clinical split-mouth study. J Clin Periodontol. 2006;33(12):908-21.doi: 10.1111/j.1600-051X.2006.00999.x.

54. Peev S, Atanasov D. Platelet-rich plasma - an accelerator of the secondary stability of immediate loaded implants. J IMAB. 2007; 13(2):38-40. 